\title{
Effect of Abciximab Therapy in Patients Undergoing Coronary Angioplasty for Acute ST-Elevation Myocardial Infarction Complicated by Cardiogenic Shock
}

\author{
Francesco De Felice, MD; Francesco Tomassini, MD; Rosario Fiorilli, MD; Andrea Gagnor, MD; \\ Antonio Parma, MD; Enrico Cerrato, MD; Carmine Musto, MD; Marco Stefano Nazzaro, MD; \\ Ferdinando Varbella, MD; Roberto Violini, MD
}

\begin{abstract}
Background: The effect of abciximab on survival in patients with ST-elevation myocardial infarction (STEMI) complicated by cardiogenic shock (CS) undergoing primary percutaneous coronary intervention (PCl) is not clear.

Methods and Results: We evaluated outcome in 410 consecutive patients with STEMI and CS who underwent PCI treated without $(n=123)$ or with $(n=287)$ abciximab. The endpoint was survival at 1 -year follow-up. The predictors of death at 1 year were also investigated. The groups with and without abciximab had similar survival at 1-year followup. Propensity score-adjusted Cox proportional hazards model identified age (adjusted hazard ratio [HR], 1.02; 95\% confidence interval [95\% Cl]: $1.01-1.03, \mathrm{P}=0.001$ ), oro-tracheal intubation ( $\mathrm{HR}, 1.49 ; 95 \% \mathrm{Cl}: 1.12-1.96, \mathrm{P}=0.05)$, post-PCI TIMI flow grade 0-1 (HR, 2.08; 95\% Cl: 1.52-2.83, $\mathrm{P}=0.0001)$ but not abciximab use (HR, $1.08 ; 95 \% \mathrm{Cl}$ : $0.70-1.60, \mathrm{P}=0.60$ ) as independent predictors of death at 1-year follow-up. Cox adjusted 1-year survival rates were $42.8 \%$ and $51.6 \%,(P=0.56)$ in patients treated without vs. with abciximab, respectively.
\end{abstract}

Conclusions: Patients with STEMI complicated by CS undergoing PCI treated with or without abciximab have similar 1-year survival rates; age, final TIMI 0-1 and oro-tracheal intubation are predictors of death. (Circ J 2015; 79: 1568-1574)

Key Words: Abciximab; Cardiogenic shock; Primary angioplasty

C ardiogenic shock (CS) is the most important complication in acute ST-elevation myocardial infarction (STEMI) because it is associated with extremely high mortality rates. ${ }^{1}$ Primary coronary intervention (PCI) is a useful strategy in the treatment of STEMI ${ }^{2}$ but it has limited benefits in patients with CS. ${ }^{3-9}$ Adjunctive abciximab treatment is associated with a high patency rate of infarct-related coronary artery, with salvage of myocardium and improvement of left ventricular function, ${ }^{10-13}$ but there are conflicting results on clinical outcome. ${ }^{14,15}$

The effect of abciximab on mortality in patients with STEMI and CS undergoing PCI is not clear. ${ }^{16-19}$ The aim of the present study was to evaluate the effect of abciximab on survival at 1-year follow-up in patients undergoing PCI for STEMI complicated by CS.

\section{Methods}

The study included all patients with STEMI and CS undergo- ing PCI, admitted in 2 high-volume catheterization laboratories. The diagnosis of STEMI was established on the basis of typical chest pain lasting $>30 \mathrm{~min}$, unrelieved by sublingual nitrates, associated with ST segment elevation $(\geq 1 \mathrm{mV}$ in $\geq 2$ limb leads or $\geq 0.2 \mathrm{mV}$ in $\geq 2$ contiguous precordial leads) or new-onset left bundle-branch block. CS was defined as systolic blood pressure $<90 \mathrm{mmHg}$ for $>30 \mathrm{~min}$ or requiring inotropes to maintain systolic blood pressure $>90 \mathrm{mmHg}$, evidence of low cardiac output with end organ hypoperfusion (eg, resting tachycardia, urine output $<30 \mathrm{ml} / \mathrm{h}$, cold extremities or altered mental status) and signs of elevated filling pressure (eg, pulmonary congestion on physical examination or chest X-ray).

PCI was performed according to the usual technique. All patients were pretreated with i.v. aspirin $300-500 \mathrm{mg}$ and 300 or $600 \mathrm{mg}$ clopidogrel. At the discretion of the operator, i.v. abciximab was administered according to the following protocol: pre-procedural bolus of $0.25 \mathrm{mg} / \mathrm{kg}$ body weight followed by continuous infusion of $0.125 \mu \mathrm{g} \cdot \mathrm{kg}^{-1} \cdot \mathrm{min}^{-1}$ for $12 \mathrm{~h}$ (up to a maximum dose of $10 \mu \mathrm{g} / \mathrm{min}$ ). Insertion of an intra-aortic

Received January 15, 2015; revised manuscript received March 16, 2015; accepted March 17, 2015; released online April 24, 2015 Time for primary review: 14 days

Interventional Cardiology Unit, S. Camillo Forlanini Hospital, Rome (F.D.F., R.F., A.P., C.M., M.S.N., R.V.); Cardiology Unit, Hospital of Infermi, Rivoli (TO) (F.T., A.G., E.C., F.V.), Italy

Mailing address: Francesco De Felice, MD, UO Cardiologia Interventistica, Azienda ASL S. Camillo Forlanini, Circonvallazione Gianicolense n 87, Roma 00152, Italy. E-mail: f.defelice@lycos.com

ISSN-1346-9843 doi:10.1253/circj.CJ-15-0053

All rights are reserved to the Japanese Circulation Society. For permissions, please e-mail: cj@j-circ.or.jp 


\begin{tabular}{lccc|}
\hline Table 1. Baseline Clinical Characteristics & & & \\
Variable & $\begin{array}{c}\text { No abciximab } \\
(\mathbf{n = 1 2 3 )}\end{array}$ & $\begin{array}{c}\text { Abciximab } \\
(\mathbf{n = 2 8 7})\end{array}$ & P-value \\
Age (years) & $73 \pm 12$ & $67 \pm 12$ & $<0.001$ \\
Men & $80(65)$ & $215(75)$ & 0.04 \\
Previous MI & $23(18)$ & $38(13)$ & 0.15 \\
Previous CABG & $7(5)$ & $8(3)$ & 0.15 \\
Previous PCI & $16(13)$ & $30(10)$ & 0.45 \\
Diabetes & $34(27)$ & $62(22)$ & 0.18 \\
Arterial hypertension & $80(65)$ & $175(61)$ & 0.43 \\
Hypercholesterolemia & $23(19)$ & $73(25)$ & 0.14 \\
Smoking & $36(30)$ & $120(42)$ & 0.01 \\
Ejection fraction (\%) & $36 \pm 10$ & $35 \pm 9$ & 0.43 \\
Infarct localization & & & 0.36 \\
$\quad$ Anterior & $68(55)$ & $175(61)$ & \\
Inferior & $37(30)$ & $83(29)$ & \\
$\quad$ Infero-lateral & $18(14)$ & $29(10)$ & 0.65 \\
Duration of pain before PCl $(\mathrm{h})$ & $6 \pm 5$ & $6 \pm 6$ & \\
\hline
\end{tabular}

Data given as $\mathrm{n}(\%)$ or mean \pm SD. Hypertension, systolic blood pressure $>140 \mathrm{mmHg}$, diastolic blood pressure $>90 \mathrm{mmHg}$, or use of blood pressure-lowering agents. Hypercholesterolemia, total cholesterol $>230 \mathrm{mg} / \mathrm{dl}$ or use of a lipid-lowering agent. CABG, coronary artery bypass graft; $\mathrm{MI}$, myocardial infarction; $\mathrm{PCl}$, percutaneous coronary intervention

balloon pump (IABP) was attempted in the case of absence of severe peripheral arterial disease and aortic regurgitation $>$ grade II in severity (on a scale of I-IV), with higher grades indicating more severe regurgitation. Thrombectomy was performed in patients with culprit vessel diameter $>2.5 \mathrm{~mm}$, with Thrombolysis in Myocardial Infarction (TIMI) flow 0-1 and a visible thrombus (TIMI thrombus grade $>3$ ) .

During PCI, i.v. bolus of unfractionated heparin was given to maintain activated clotting time $\geq 300 \mathrm{~s}$ ( $250 \mathrm{~s}$ in the case of abciximab). All patients discharged alive were treated with aspirin $(100 \mathrm{mg})$ indefinitely and clopidogrel $(75 \mathrm{mg})$ daily for 6-12 months.

Follow-up protocol included evaluation at hospital discharge and a clinical visit thereafter at 1 and 12 months. The endpoint of the study was survival at 1 year.

In-hospital incidence of major and moderate bleeds and vascular complications at 30 days were also recorded. Major bleeding was defined as intracranial or clinically significant (drop in hemoglobin $>5 \mathrm{~g} / \mathrm{dl}$ ). Vascular complications were defined as the need for surgical repair, hematoma diameter $>10 \mathrm{~cm}$, pseudo-aneurism or arterio-venous fistula at the access site.

The number of critically narrowed coronary arteries was evaluated. Angiography of coronary narrowing was done on enddiastolic frame demonstrating the stenosis in its more severe view. The view with the least foreshortening was selected for analysis. Initial and final flow rate in the infarct-related coronary artery was graded according to TIMI classification.

\section{Statistical Analysis}

Retrospective analysis of data prospectively collected according to internal protocols was performed. Data are presented as mean $\pm \mathrm{SD}$ or percentages. Comparisons between group treated with vs. without abciximab were performed using t-test for continuous data, and the chi-squared test or Fisher exact test for categorical data. Logistic regression was performed to determine the independent correlates of death at 30-day follow-up. Cox proportional hazards model was used to determine the independent correlates of the primary endpoint at 1 year. Linearity and proportionality assumptions were verified accord- ing to Mantel-Haenszel method. The C-statistic was calculated to evaluate the goodness of fit of the multivariate model. Coxadjusted survival curves were developed using the KaplanMeier method. We used propensity score method to compensate for the non-randomized design of the study. Individual propensity, defined as the conditional probability of obtaining treatment with or without abciximab, was estimated using logistic regression modeling with baseline covariates shown in Tables 1,2 as potential predictors of survival. Adjusted relative risk was estimated from models in which propensity score for abciximab use was entered as a covariate. A test of interaction was performed between abciximab treatment and possible confounding factors. Analysis was performed using SPSS version 17.0 (SPSS, Chicago, IL, USA). Statistical significance was accepted at $\mathrm{P}<0.05$.

\section{Results}

From January 2002 to October 2011, 410 consecutive patients (mean age, $68 \pm 12$ years) with STEMI complicated by CS underwent coronary angiography and immediate PCI in 2 highvolume centers.

Baseline characteristics are listed in Table 1 . The group without abciximab included a significantly lower number of women and smokers. Angiographic and procedural variables are given in Table 2. Multivessel coronary artery disease was present in 297 patients $(74 \%)$ without significant differences between the groups. Multivessel PCI was performed in 105 patients (26\%). Patients without abciximab had higher incidence of TIMI flow grade $0-1$ after procedure $(24 \%$ vs. $12 \%, \mathrm{P}=0.005)$ and were less likely to receive IABP, thrombus aspiration and oro-tracheal intubation.

Mortality rates at 30-day and 1-year follow-up in patients with and without abciximab are reported in Table 2. There were 42 and 14 deaths among 77 and 28 patients treated with and without abciximab during multivessel PCI, respectively, $(\mathrm{P}=0.68)$.

Fifteen patients were lost at 1-year follow-up without differences between the groups. 


\begin{tabular}{|c|c|c|c|}
\hline Variable & $\begin{array}{c}\text { No abciximab } \\
(n=123)\end{array}$ & $\begin{array}{c}\text { Abciximab } \\
(\mathrm{n}=287)\end{array}$ & P-value \\
\hline Target vessel & & & 0.64 \\
\hline Left main & $14(11)$ & $36(12)$ & \\
\hline Left anterior descending & $52(42)$ & $141(49)$ & \\
\hline Circumflex & $17(14)$ & $30(10)$ & \\
\hline Right & $37(30)$ & $75(26)$ & \\
\hline CABG & $3(2)$ & $5(2)$ & \\
\hline Treated coronary segment & & & 0.15 \\
\hline Ostial & $3(2)$ & $8(3)$ & \\
\hline Proximal & $67(54)$ & $189(66)$ & \\
\hline Middle & $35(28)$ & $62(21)$ & \\
\hline Distal & $18(15)$ & $28(10)$ & \\
\hline No. diseased vessels & & & 0.46 \\
\hline 1 & $37(30)$ & $76(26)$ & \\
\hline 2 & $43(35)$ & $92(32)$ & \\
\hline 3 & $43(35)$ & $119(41)$ & \\
\hline Chronic total occlusion & $34(27)$ & $84(29)$ & 0.79 \\
\hline No. treated vessels & & & 0.54 \\
\hline 1 & $96(78)$ & $209(73)$ & \\
\hline 2 & $24(19)$ & $69(24)$ & \\
\hline 3 & $3(2)$ & $9(3)$ & \\
\hline TIMI flow grade before intervention & & & 0.41 \\
\hline 0 & $95(77)$ & $218(76)$ & \\
\hline 1 & $7(5)$ & $26(9)$ & \\
\hline 2 & $11(9)$ & $16(5)$ & \\
\hline 3 & $10(8)$ & $27(9)$ & \\
\hline TIMI flow grade after intervention & & & 0.0037 \\
\hline 0 & $20(16)$ & $16(5)$ & \\
\hline 1 & $10(8)$ & $22(7)$ & \\
\hline 2 & $12(10)$ & $23(8)$ & \\
\hline 3 & $81(65)$ & $226(79)$ & \\
\hline Intervention & & & 0.05 \\
\hline Bare metal stent & $71(58)$ & $189(65)$ & \\
\hline Drug-eluting stent & $29(23)$ & $60(21)$ & \\
\hline Percutaneous only balloon angioplasty & $14(11)$ & $32(11)$ & \\
\hline Failure to cross the occlusion with the wire & $9(7)$ & $6(2)$ & \\
\hline Thrombus aspiration & $22(18)$ & $103(36)$ & 0.0003 \\
\hline IABP & $38(31)$ & $214(74)$ & 0.0001 \\
\hline Temporary pacemaker & $34(27)$ & $55(19)$ & 0.05 \\
\hline Oro-tracheal intubation & $55(44)$ & $98(34)$ & 0.04 \\
\hline Death at 30 days & $72(58)$ & $115(40)$ & 0.0005 \\
\hline Death at 1 year & $75(61)$ & $131(45)$ & 0.001 \\
\hline Lost at 1 year & $7(5)$ & $8(3)$ & 0.15 \\
\hline Bleeding & $4(3)$ & $5(1)$ & 0.46 \\
\hline
\end{tabular}

Data given as n (\%). IABP, intra-aortic balloon pump; TIMI, Thrombolysis in Myocardial Infarction. Other abbreviations as in Table 1.

The following variables were included in the multivariate logistic regression model: age, sex, previous $\mathrm{MI}$, previous coronary artery bypass graft (CABG), previous PCI, smoking, diabetes, hypercholesterolemia, left ventricular ejection fraction, target vessel, treated coronary segment, number of diseased and treated vessels, TIMI flow grade before and after PCI, coronary thrombus aspiration, aortic counterpulsation, oro-tracheal intubation, temporary pacemaker and abciximab. Logistic regression identified age, (OR, 1.05; 95\% confidence interval [95\% CI]: 1.03-1.07, $\mathrm{P}<0.0001)$, oro-tracheal intubation $(\mathrm{OR}$,
2.74; 95\% CI: 4.40-1.70, P=0.0001), TIMI flow grade 0-1 after PCI (OR, 10.2; 95\% CI: 5.60-18.50, P<0.0001) and left main (OR, 2.6; 95\% CI: 5.2-1.3, $\mathrm{P}<0.007)$ but not abciximab (OR, 0.72 ; 95\% CI: $1.2-0.4, \mathrm{P}=0.20)$ as predictors of death at 30 days. The following variables were identified as predictors of propensity to abciximab use: younger age (OR, 0.96; $95 \%$ CI: 0.94-0.98; $\mathrm{P}=0.0001)$, absence of IABP (OR, 0.15; $95 \%$ CI: $0.093-0.25 ; \mathrm{P}=0.0001)$, and absence of oro-tracheal intubation (OR, 0.49; 95\% CI: 0.30-0.81; $\mathrm{P}<0.005)$. The following variables were included in the multivariate Cox proportional 


\begin{tabular}{|c|c|c|c|}
\hline Variable & HR & $95 \% \mathrm{Cl}$ & P-value \\
\hline Age & 1.02 & $1.01-1.03$ & 0.001 \\
\hline Sex & 1.32 & $0.99-1.77$ & 0.061 \\
\hline Previous $\mathrm{PCl}$ & 1.12 & $0.70-1.70$ & 0.62 \\
\hline Previous CABG & 0.72 & $0.38-1.37$ & 0.32 \\
\hline Smoking & 1.55 & $1.15-2.09$ & 0.04 \\
\hline Diabetes mellitus & 0.95 & $0.69-1.31$ & 0.75 \\
\hline Arterial hypertension & 0.92 & $0.69-1.22$ & 0.56 \\
\hline Hypercholesterolemia & 1.54 & $1.07-2.22$ & 0.02 \\
\hline EF & 1.01 & $0.97-1.06$ & 0.52 \\
\hline Left main vs. other vessels & 1.30 & $0.9-1.9$ & 0.16 \\
\hline \multicolumn{4}{|l|}{ Treated coronary segment } \\
\hline Ostial vs. proximal & 0.99 & $0.64-1.55$ & 0.99 \\
\hline Ostial vs. mid & 1.01 & $0.62-1.66$ & 0.96 \\
\hline Ostial vs. distal & 0.91 & $0.37-2.24$ & 0.84 \\
\hline Three-vessel vs. 1- and 2-vessel disease & 1.36 & $1.04-1.79$ & 0.027 \\
\hline Chronic total occlusion & 1.27 & $0.95-1.7$ & 0.108 \\
\hline \multicolumn{4}{|l|}{ Treated vessels } \\
\hline 3 vs. 1 & 1.60 & $0.82-3.14$ & 0.17 \\
\hline 3 vs. 2 & 1.56 & $0.76-3.17$ & 0.23 \\
\hline \multicolumn{4}{|l|}{ TIMI flow grade before $\mathrm{PCI}$} \\
\hline 3 vs. 0 & 1.20 & $0.77-1.87$ & 0.43 \\
\hline 3 vs. 1 & 1.53 & $0.77-3.04$ & 0.22 \\
\hline 3 vs. 2 & 1.06 & $0.55-2.05$ & 0.85 \\
\hline TIMI flow grade $0-1$ after $\mathrm{PCl}$ & 2.08 & $1.52-2.83$ & 0.0001 \\
\hline \multicolumn{4}{|l|}{ Intervention } \\
\hline DES vs. POBA & 1.48 & $0.93-2.36$ & 0.09 \\
\hline DES vs. BMS & 1.04 & $0.71-1.54$ & 0.82 \\
\hline Thrombus aspiration & 1.47 & $1.04-2.06$ & 0.027 \\
\hline IABP & 0.82 & $0.63-1.1$ & 0.173 \\
\hline Temporary pacemaker & 1.43 & $1.04-1.98$ & 0.028 \\
\hline Oro-tracheal intubation & 1.49 & $1.12-1.96$ & 0.05 \\
\hline Abciximab & 0.72 & $0.54-0.96$ & 0.0025 \\
\hline
\end{tabular}

BMS, bare metal stent; DES, drug-eluting stent; EF, ejection fraction; POBA, plain old balloon angioplasty. Other abbreviations as in Tables 1,2.

hazard model: age, sex, previous MI, previous CABG, previous PCI, smoking, diabetes, hypercholesterolemia, left ventricular ejection fraction, treated vessel, treated coronary segment, number of diseased and treated vessels, TIMI flow grade before and after PCI, coronary thrombus aspiration, aortic counterpulsation, oro-tracheal intubation, temporary pacemaker and abciximab. Data regarding univariate and multivariate analysis at 1-year follow-up are given in Tables 3,4, respectively. The Cox proportional hazards model identified age, TIMI flow grade $0-1$ after PCI and oro-tracheal intubation but not abciximab as independent predictors of death at 1-year follow-up. The C-statistic for the whole model was 0.80 . These results did not significantly change after adjustment for propensity score given that Cox proportional hazard model identified the same aforementioned variables but not abciximab as independent predictors of survival at 1-year follow-up (Table 5).

Cox-adjusted survival rates were $45.7 \%$ vs. $58.0 \%$, and $42.8 \%$ vs. $51.6 \%(\mathrm{P}=0.56)$ at 30 days and 1 year in patients treated without or with abciximab, respectively (Figure).

A test for interaction was performed but it did not show any significant correlation between abciximab and TIMI flow 0-1 after PCI (hazard ratio [HR], 0.93; 95\% CI: 0.50-1.73; P=0.82),
IABP (HR, 0.96; 95\% CI: 0.64-1.45; $\mathrm{P}=0.87$ ) and thrombus aspiration (HR, 1.37; 95\% CI: $0.93-2.03 ; \mathrm{P}=0.11$ ) regarding mortality at 1 year.

\section{Discussion}

We found that abciximab apparently reduces 1-year mortality in patients undergoing PCI for STEMI complicated by CS. This result is probably due to a tendency to reduce its use in higher risk patients, because it is no longer present when propensity score analysis was applied to abciximab treatment. Moreover, abciximab was not identified as a predictor of survival during 1-year follow-up on Cox proportional hazard modeling.

There are poor and conflicting data regarding the effectiveness of abciximab in patients undergoing PCI in the setting of STEMI complicated by CS. Antoniucci et al, in a cohort of 77 consecutive patients, found lower mortality rate in the abciximab group compared with the group in which abciximab was contraindicated. ${ }^{16}$ Furthermore, abciximab was the only variable independently related to 1-month mortality. Although the study was performed in the ticlopidine and bare metal stent era, the abciximab group had a surprisingly low mortality rate 


\begin{tabular}{|c|c|c|c|}
\hline Variable & HR & $95 \% \mathrm{Cl}$ & P-value \\
\hline Age & 1.02 & $1.01-1.04$ & 0.001 \\
\hline Sex & 1.15 & $0.68-2.01$ & 0.46 \\
\hline Previous myocardial infarction & 0.93 & $0.47-1.81$ & 0.15 \\
\hline Previous CABG & 0.72 & $0.34-1.53$ & 0.50 \\
\hline Previous $\mathrm{PCl}$ & 0.73 & $0.43-1.77$ & 0.64 \\
\hline Smoking & 0.88 & $0.53-1.25$ & 0.14 \\
\hline Diabetes & 1.15 & $0.64-2.11$ & 0.79 \\
\hline Hypercholesterolemia & 0.98 & $0.49-1.90$ & 0.13 \\
\hline Ejection fraction & 1.02 & $0.64-2.03$ & 0.14 \\
\hline Treated ostial coronary segment & 1.04 & $0.65-1.45$ & 0.91 \\
\hline Three vessel disease & 1.20 & $0.74-1.56$ & 0.32 \\
\hline Left main & 1.18 & $0.79-2.19$ & 0.19 \\
\hline Multivessel PCl & 0.49 & $0.86-2.58$ & 0.87 \\
\hline TIMI flow grade before intervention $0-1$ & 1.09 & $0.66-2.14$ & 0.58 \\
\hline TIMI flow grade after intervention $0-1$ & 2.18 & $1.50-3.60$ & 0.0001 \\
\hline Thrombus aspiration & 0.87 & $0.57-2.01$ & 0.20 \\
\hline IABP & 0.76 & $0.38-1.52$ & 0.73 \\
\hline Oro-tracheal intubation & 1.47 & $1.27-1.89$ & 0.006 \\
\hline Temporary pacemaker & 0.98 & $0.49-1.95$ & 0.28 \\
\hline Abciximab & 0.53 & $0.04-6.9$ & 0.62 \\
\hline
\end{tabular}

Abbreviations as in Tables 1,2.

\begin{tabular}{|c|c|c|c|}
\hline Variable & HR & $95 \% \mathrm{Cl}$ & P-value \\
\hline Age & 1.02 & $1.01-1.03$ & 0.001 \\
\hline Oro-tracheal intubation & 1.49 & $1.12-1.96$ & 0.05 \\
\hline TIMI flow grade $0-1$ after $\mathrm{PCI}$ & 2.08 & $1.52-2.83$ & 0.0001 \\
\hline Propensity to abciximab use & 1.08 & $0.70-1.60$ & 0.60 \\
\hline
\end{tabular}

${ }^{\dagger}$ After propensity score adjustment. Abbreviations as in Tables 1,2.

(18\%). The small sample size, the lower risk profile (younger age in the abciximab group) and the bias of operator discretion in contraindicating abciximab in an unusually high number of patients $(43 \%)$ may justify the different results.

Giri et al noted a better composite endpoint of death, MI and target vessel revascularization in the abciximab than non-abciximab group in a small series of 113 consecutive patients with AMI and CS treated by PCI with a low rate of stent implantation $(50 \%) .{ }^{17}$ Although abciximab use was associated with a higher survival and represented a favourable independent predictor of clinical outcome on multivariate analysis, these patients also had a higher rate of stent implantation, suggesting that the interaction of the drug with the device provides better results than abciximab alone. This view was confirmed by Chan et al, who concluded that treatment with the combination of stent and abciximab resulted in higher procedural TIMI 3 flow rate and long-term survival benefit in patients with STEMI and CS undergoing PCI. ${ }^{18}$ Moreover, stent use, but not abciximab, was a predictor of mortality during short- and long-term follow-up.

More recently, the open randomized multicenter Prague-7 study did not show any benefit of routine pre-procedural compared with selective abciximab use in patients with CS undergoing primary PCI. ${ }^{19}$ A subanalysis of the study in the group of mechanically ventilated patients suggested that abciximab is associated with better angiographic results, but also with a higher incidence of bleeding. ${ }^{20}$ Although biased by the small sample size and a considerable cross-over (35\% of patients) to abciximab in the standard therapy group, the results of that study seem to be in line with the present ones. It seems that the lack of clinical benefit of abciximab and other medical treatments combined with invasive strategy may be not due to inefficacy of the drugs themselves but to the extensive metabolic derangements in CS complicating STEMI.

We also found no differences between the groups treated with or without abciximab in major bleeds and vascular complications, although the number of patients is too low to draw any conclusion about the safety of abciximab in patients with STEMI and CS.

Age, oro-tracheal intubation and final TIMI 3 flow grade were identified as independent predictors of 1-year survival in patients with STEMI complicated by CS undergoing PCI. Age is one of the stronger independent predictors of death. ${ }^{8,21,22}$ Associated comorbidities, severity of coronary artery disease, procedural failure and increased non-cardiac complications may explain the adverse impact of advanced age on survival. Unfortunately the influence of these factors on mortality is not affected by abciximab treatment. Oro-tracheal intubation was a predictor of reduced survival in the present study. It often reflects worse clinical presentation in patients with STEMI and CS, including previous cardiac arrest and hemodynamic impairment. In these cases gastrointestinal absorption of orally administered drugs, such as thienopyridine, may be attenuated 


\section{Adjusted survival according to abciximab use}

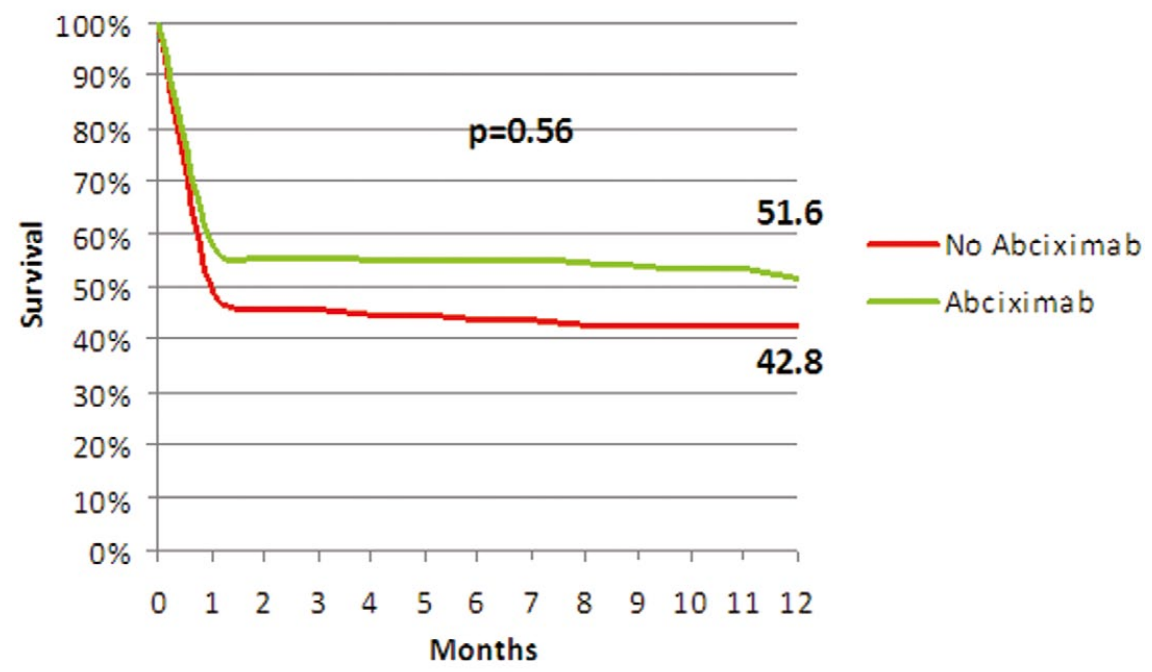

Number of patients at risk

No Abciximab 123

Abciximab

Months since index procedure

$\begin{array}{rrr}49 & 48 & 44 \\ 165 & 161 & 157 \\ 2 & 4 & 6\end{array}$

$\begin{array}{rrr}43 & 42 & 41 \\ 155 & 153 & 151 \\ 8 & 10 & 12\end{array}$

Figure. Survival curves according to age. Cox adjusted survival curves in patients with ST-elevation myocardial infarction complicated by cardiogenic shock undergoing primary percutaneous coronary intervention treated with or without abciximab.

or reduced by concomitant interaction of vasopressors, opiates, or liver dysfunction, minimizing the benefits of PCI with stent implantation. Although i.v. abciximab may theoretically protect these patients from early stent thrombosis, its impact on mortality was not relevant in the present study, suggesting that this mechanism was not significant in clinical outcome in patients with STEMI and CS undergoing PCI.

Final coronary TIMI 3 flow grade is associated with higher 30-day and 1-year survival rates. ${ }^{8,22}$ These results were confirmed by a previous study, in which failed reperfusion also predicted higher in-hospital mortality in patients with CS. ${ }^{22}$ Although it has been claimed that abciximab ameliorates postprocedural TIMI flow grade in STEMI patients undergoing PCI, a clear effect on survival in patients with CS was not seen in the present study. The absence of clinical benefits of abciximab may be due to the fact that final TIMI 0-1 flow grade depends on may different factors: duration of coronary occlusion, which is an important determinant of infarct size; presence of older and partially organized coronary thrombus with distal embolization; delay or failure in reperfusion due to technical difficulties; and early death during PCI due to irreversible hemodynamic impairment.

\section{Conclusions}

In patients with STEMI complicated by CS undergoing PCI, abciximab treatment does not appear to have clinical benefits during 1-year follow-up.

\section{Study Limitations}

The study was retrospective but, in our view, adds important information about the impact of abciximab on survival in a real-world population undergoing PCI for STEMI and CS. We tried to compensate for the absence of randomization by using the propensity score method. The low number of patients in the present study, although the highest ever reported to our knowledge, could have affected the results because the sample size did not provide adequate statistical power to detect differences between groups. Calculation of required sample size, however, is difficult due to the lack of similar studies in the literature. Information on serum lactate, kidney function, rates of cardiac arrest with resuscitation prior to admission and major laboratory data were not available in all patients. The incidence of ultrafiltration was not recorded. Patients treated with prasugrel or ticagrelor were not included in the present study. ${ }^{23}$ Morphological analysis of organized thrombus, calcification and plaque components in the aspirated material was not performed. ${ }^{24}$ Advanced left ventricular support systems (Impella, Tandem Heart and extracorporeal membrane oxygenator) were not used in the present study, although further investigations are required to verify the effectiveness of these devices in patients with STEMI and CS. ${ }^{25-29}$

Finally the present results should be validated in a larger multicenter study.

\section{Disclosures}

The authors report no financial relationships or conflicts of interest regarding the content herein. 


\section{References}

1. Carnendran L, Abboud R, Sleeper LA, Gurunathan R, Webb JG, Menon V, et al. Trends in cardiogenic shock: Report from the SHOCK Study. The SHould we emergently revascularize Occluded Coronaries for cardiogenic shocK? Eur Heart J 2001; 22: 472-478.

2. Hochman JS, Sleeper LA, Webb JG, Sanborn TA, White HD, Talley $\mathrm{JD}$, et al. Early revascularization in acute myocardial infarction complicated by cardiogenic shock: SHOCK Investigators: Should we emergently revascularize occluded coronaries for cardiogenic shock. $N$ Engl J Med 1999; 341: 625-634.

3. Hochman JS, Sleeper LA, White HD, Dzavik V, Wong SC, Menon $\mathrm{V}$, et al; for the SHOCK Investigators. One-year survival following early revascularization for cardiogenic shock. JAMA 2001; 285: 190 192.

4. Hochman JS, Sleeper LA, Webb JG, Dzavik V, Buller CE, Aylward $\mathrm{P}$, et al; for the SHOCK Investigators. Early revascularization and long-term survival in cardiogenic shock complicating acute myocardial infarction. JAMA 2006; 295: 2511-2515.

5. Dzavik V, Sleeper LA, Cocke TP, Moscucci M, Saucedo J, Hosat S, et al; SHOCK Investigators. Early revascularization is associated with improved survival in elderly patients with acute myocardial infarction complicated by cardiogenic shock: A report from the SHOCK Trial Registry. Eur Heart J 2003; 24: 828-837.

6. Gasior M, Slonka G, Wilczek K, Gierlotka M, Ruzyllo W, Zembala $\mathrm{M}$, et al. Comparison of invasive and non-invasive treatment strategies in older patients with acute myocardial infarction complicated by cardiogenic shock (from the Polish Registry of Acute Coronary Syndromes: PL-ACS). Am J Cardiol 2011; 107: 30-36.

7. Lim HS, Farouque O, Andrianopoulos N, Yan BP, Lim CC, Brennan AL, et al; Melbourne Interventional Group. Survival of elderly patients undergoing percutaneous coronary intervention for acute myocardial infarction complicated by cardiogenic shock. J Am Coll Cardiol Interv 2009; 2: 146-152.

8. Tomassini F, Gagnor A, Migliardi A, Tizzani E, Infantino V, Giolitto $\mathrm{S}$, et al. Cardiogenic shock complicating acute myocardial infarction in the elderly: Predictors of long-term survival. Catheter Cardiovasc Interv 2011; 78: 505-511.

9. Jeger RV, Urban P, Harkness SM, Tseng CH, Stauffer JC, Lejemtel $\mathrm{TH}$, et al. Early revascularization is beneficial across all ages and a wide spectrum of cardiogenic shock severity: A pooled analysis of trials. Acute Card Care 2011; 13: 14-20.

10. Montalescot G, Barragan P, Wittenberg O, Ecollan P, Elhadad S, Villain P, et al. Platelet glycoprotein IIb/IIIa inhibition with coronary stenting for acute myocardial infarction. N Engl J Med 2001; 344: $1895-1903$.

11. Schoming A, Kastrati A, Dirschinger J, Mehilli J, Schricke U, Pache $\mathrm{J}$, et al. Coronary stent plus platelet glycoprotein IIb/IIIa blockade compared with tissue plasminogen activator in acute myocardial infarction. N Engl J Med 2000; 343: 385-391.

12. Kastrati A, Mehilli J, Dirschinger J, Schricke U, Neverve J, Pache J, et al. Myocardial salvage after coronary stenting plus abciximab versus fibrinolysis plus abciximab in patients with acute myocardial infarction: A randomised trial. Lancet 2002; 359: 920-925.

13. Kastrati A, Mehilli J, Schlotterbeck K, Dotzer F, Dirschinger J, Schmitt $\mathrm{C}$, et al. Early administration of reteplase plus abciximab versus abciximab alone in patients with acute myocardial infarction referred for percutaneous coronary intervention: A randomized controlled trial. JAMA 2004; 291: 947-954.

14. Mehilli J, Kastrati A, Schulz S, Früngel S, Nekolla SG, Moshage W, et al; for the Bavarian Reperfusion Alternatives Evaluation-3 (BRAVE 3) Study Investigators. Abciximab in patients with acute ST-segment elevation myocardial infarction undergoing primary percutaneous coronary intervention after clopidogrel loading: A randomized dou- ble blind trial. Circulation 2009; 119: 1933-1340.

15. Ellis SG, Tendera M, de Belder MA, van Boven AJ, Widimsky P, Janssens L, et al; FINESSE Investigators. Facilitated PCI in patients with ST-elevation myocardial infarction. $N$ Engl J Med 2008; 358: $2205-2217$.

16. Antoniucci D, Valenti R, Migliorini A, Moschi G, Trapani M, Dovellini EV, et al. Abciximab therapy improves survival in patients with acute myocardial infarction complicated by early cardiogenic shock undergoing coronary artery stent implantation. Am J Cardiol 2002; 90: 353-357.

17. Giri S, Mitchel J, Azar RR, Kiernan FJ, Fram DB, McKay RG, et al. Results of primary percutaneous transluminal coronary angioplasty plus abciximab with or without stenting for acute myocardial infarction complicated by cardiogenic shock. Am J Cardiol 2002; 89: $126-$ 131.

18. Chan AW, Chew DP, Bhatt DL, Moliterno DJ, Topol EJ, Ellis SG. Long-term mortality benefit with the combination of stents and abciximab for cardiogenic shock complicating acute myocardial infarction. Am J Cardiol 2002; 89: 132-136.

19. Tousek P, Rokyta R, Tesarova J, Pudil R, Belohlavek J, Stasek J, et al. Routine upfront abciximab versus standard periprocedural therapy in patients undergoing primary percutaneous coronary intervention for cardiogenic shock: The PRAGUE-7 Study: An open randomized multicentre study. Acute Card Care 2011; 13: 116-122.

20. Rokyta R, Pechman V, Tousek P, Pudil R, Lhotska J, Widimsky P. Routine pretreatment with abciximab versus standard periprocedural therapy in mechanically ventilated cardiogenic shock patients undergoing primary percutaneous coronary intervention: Subanalysis of the PRAGUE-7 study. Exp Clin Cardiol 2013; 18: 81-84.

21. De Felice F, Guerra E, Fiorilli R, Parma A, Musto C, Nazzaro MS, et al. One-year clinical outcome of elderly patients undergoing angioplasty for ST-elevation myocardial infarction complicated by cardiogenic shock: The importance of 3-vessel disease and final TIMI-3 flow grade. J Invasive Cardiol 2014; 26: 114-118.

22. Sutton AG, Finn P, Hall JA, Harcombe AA, Wright RA, de Belder MA. Predictors of outcome after percutaneous treatment for cardiogenic shock. Heart 2005; 91: 339-344.

23. Saito S, Isshiki T, Kimura T, Ogawa H, Yokoi H, Nanto S, et al. Efficacy and safety of adjusted-dose prasugrel compared with clopidogrel in Japanese patients with acute coronary syndrome: The PRASFITACS study. Circ J 2014; 78: 1684-1692.

24. Nishihira K, Hatakeyama K, Shibata Y, Kitamura K, Asada Y. Organized thrombus in aspirated coronary materials can predict in-hospital mortality of patients with acute myocardial infarction. Circ J 2013; 77: $1275-1280$.

25. Barone-Rochette G, Vanzetto G, Fluttaz A, Marlière S, Bouvaist H, Durand M, et al. Cardiogenic shock due to unprotected left main coronary artery thrombosis in the era of mechanical circulatory support. Int J Cardiol 2011; 148: 394-396.

26. Kagawa E, Dote K, Kato M, Sasaki S, Nakano Y, Kajikawa M, et al. Should we emergently revascularize occluded coronaries for cardiac arrest? Rapid-response extracorporeal membrane oxygenation and intra-arrest percutaneous coronary intervention. Circulation 2012; 126: $1605-1613$.

27. Beurtheret S, Mordant P, Paoletti X, Marijon E, Celermajer DS, Léger $\mathrm{P}$, et al. Emergency circulatory support in refractory cardiogenic shock patients in remote institutions: A pilot study (the cardiac-RESCUE program). Eur Heart J 2013; 34: 112-120.

28. Gafoor S, Franke J, Lam S, Reinartz M, Bertog S, Vaskelyte L, et al. Devices in heart failure. Circ J 2015; 79: 237-244.

29. Kajimoto M, Ledee DR, Xu C, Kajimoto H, Isern NG, Portman MA. Triiodothyronine activates lactate oxidation without impairing fatty acid oxidation and improves weaning from extracorporeal membrane oxygenation. Circ J 2014; 78: 2867-2875. 